\title{
Soil water retention behaviour for an instrumented embankment
}

\author{
D.G. Toll ${ }^{1, a}$, P.N. Hughes ${ }^{1}$, J.D. Asquith ${ }^{1}$ \\ ${ }^{1}$ School of Engineering and Computing Sciences, Durham University, Durham DH1 3LE, UK
}

\begin{abstract}
The research project iSMART (Infrastructure Slopes: Sustainable Management And Resilience Assessment) has been established as a collaboration between six UK academic partners and 11 asset owners and industrial partners to investigate the impacts of weather and climate on infrastructure slopes. One of the sites being monitored within the iSmart project is an instrumented embankment to investigate the response to changing climatic conditions. The BIONICS embankment was built at Nafferton farm in North East England. The fill material was a glacial till (Durham Lower Boulder Clay), a common fill material in North East England and hence representative of earthwork construction. The fill material can be classified as a sandy clay of intermediate plasticity. The soil water retention curves (SWRC) for the BIONICS soil have been measured in the laboratory using novel high suction tensiometer based equipment. These are compared to field observations of suction and water content obtained in the field. The first cycle of drying and wetting compares reasonably well between the laboratory and the field. However, subsequent drying in the field shows a significantly different path to that observed in the laboratory.
\end{abstract}

\section{Introduction}

The water retention behaviour of soils is an essential aspect of understanding the unsaturated behaviour of soil materials [1]. It represents the relationship between suction and water content (which can be gravimetric or volumetric) or may be represented in terms of degree of saturation. This paper reports results obtained using a relatively new method of measurement for soil water retention curves, using high capacity tensiometers.

Results are presented for a sandy clay fill material obtained as part of an investigation of the impacts of climate on infrastructure slopes. The project iSmart (Infrastructure Slopes: Sustainable Management And Resilience Assessment: www.ismartproject.org) has been established as a collaboration between six UK academic partners (Universities of Newcastle, Durham, Loughborough, Queen's Belfast, Southampton and British Geological Survey) and 11 asset owners and industrial partners to investigate the impacts of weather and climate on infrastructure slopes.

The soil used in this study was a glacial till (Durham Lower Boulder Clay) obtained from fill material used in the construction of an experimental embankment (called the BIONICS embankment) constructed at Nafferton Farm in North East England [2]. The fill material is a glacial till (Durham Lower Boulder Clay), a common fill material in North East England and hence representative of earthwork construction in North East England. Field measurements are being obtained from a number of sites (embankments and cuttings) across the UK. Laboratory measurements are needed to interpret and understand the field observations and provide input parameters for numerical modelling.

Field measurements have been carried out at the BIONICS embankment that allow determination of the field soil water retention curves. The laboratory measurements obtained using the tensiometer technique are compared to field observations of suction and water content obtained from the BIONICS embankment.

\section{Material tested}

A sandy clay soil used in the construction of the BIONICS embankment at Nafferton Farm in North East England was prepared by sieving through a $2.8 \mathrm{~mm}$ sieve to remove the larger particles to reduce the variation in properties. The sieved material comprised $30 \%$ sand, $35 \%$ silt and $35 \%$ clay, i.e., a sandy clay soil. The Liquid Limit was $43.3 \%$ and the Plastic Limit was $23.7 \%$, resulting in a Plasticity Index of 19.6 [3]. The particle density was $2.66 \mathrm{Mg} / \mathrm{m}^{3}$.

Specimens for testing were prepared by compaction into a $100 \mathrm{~mm}$ diameter mould using the equivalent compactive effort of the standard Proctor test (BS light compaction, [4]). Samples were compacted wet of optimum at a water content of $24 \%$. This resulted in specimens close to saturation (degree of saturation, $\mathrm{Sr}>95 \%$ ). From the larger compacted samples, smaller specimens having a diameter of $75 \mathrm{~mm}$ and a thickness of $20 \mathrm{~mm}$ were trimmed from the $100 \mathrm{~mm}$ diameter compacted samples for testing in the tensiometer equipment.

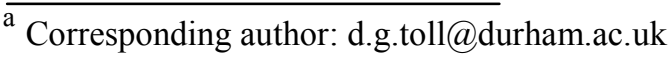




\section{The Durham SWRC Equipment}

Measurements of the soil water retention curves (SWRC) have been carried out using the Durham SWRC equipment. The experimental apparatus allows continuous measurements of water content, suction and volume change [5, Erreur! Source du renvoi introuvable.]. The apparatus is made up of a PVC frame (Figures $1 \& 2$ ) placed on an electronic balance to determine the change in sample weight and hence water content (as used by Lourenço et al. [7, 8]).

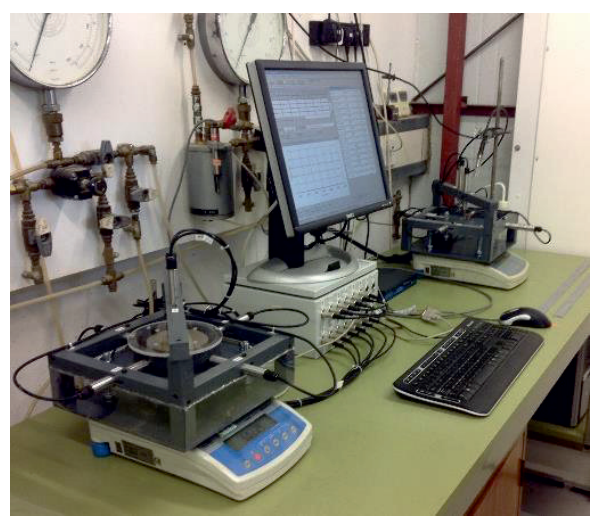

Figure 1. The Durham SWRC equipment, showing the frame sitting on the electronic balance and connected to the datalogging system.

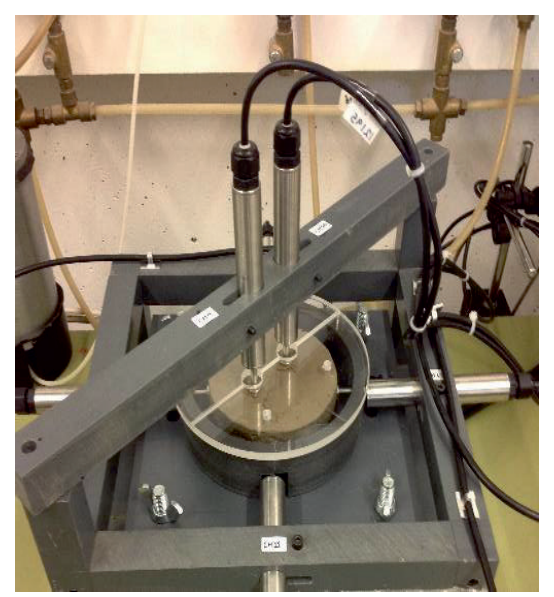

Figure 2. The Durham SWRC equipment, showing the PVC frame holding six LVDTs to measure volume change.

For volume change measurements, four displacement transducers were installed through the four outside beams of the frame to measure radial displacement of the specimen and two more displacement transducers were fitted through the upper beam to measure axial displacement (change in height) (Figure 2). Volume change of the specimen could then be calculated from the radial and axial deformations.

A high suction tensiometer developed at Durham University [9, 9] was used to measure suction. These devices have been used for direct measurement of suction as large as $2000 \mathrm{kPa}$. The tensiometer was fitted through a hole in the support plate, with a tight fitting rubber O-ring to secure it in place. All transducers were connected to a real-time data acquisition system [11].
Using the tensiometer technique, suction can be measured in samples either dried continuously while exposed to the atmosphere (continuous procedure) or by drying in stages (stage procedure). In the stage procedure, the specimen is sealed and allowed to equalise internally after each period of drying. Both approaches are quicker than traditional methods for obtaining SWRCs (e.g. pressure plate).

\section{Field measurements of water retention}

Glendinning et al. [12] describe field measurements of suction and water content measured in the BIONICS embankment. Suctions were measured using MPS-1 dielectric water potential sensors produced by Decagon Ltd. These devices can measure soil suction in the range of 10 to $600 \mathrm{kPa}$ and are accurate to $20 \%$ of total soil suction measured.

Volumetric water content was measured using ML2 Theta probes produced by Delta-T Devices. The sensors for suction and water content were positioned at the base, mid-point and top of the slope at depths of 0.5 and $1 \mathrm{~m}$ and measurements were taken hourly.

The field measurements for suction and water content at a depth of $0.5 \mathrm{~m}$ for March-June 2009 (a drying period), August-November 2009 (a wetting period) and AprilJune 2010 (a drying period) were interpreted as gravimetric water content vs. suction curves [12]. These data will be compared with the laboratory measurements of SWRC obtained from tensiometer devices in the laboratory.

\section{Comparison of laboratory and field SWRCs}

A series of laboratory measured soil water retention curves obtained using the tensiometer technique is plotted in Figure $3[6,13]$. The majority of results were obtained by continuous drying. Two tests shown were determined by stage drying. Good agreement is shown between all sets of results over the range $1-1000 \mathrm{kPa}$.

One set of tests followed the SWRC over two complete cycles of drying and wetting [13]. Figure 3 shows that for each full cycle (drying and wetting) the hysteretic behaviour is quite different. For the first cycle, the difference between the primary drying curve and the subsequent wetting curve is much larger than for the second cycle. The last three paths (wetting-dryingwetting) lie very close to each other.

The field data obtained by Glendinning et al. [12] is plotted in Figure 3 for comparison with the laboratory data. It can be seen that the drying period (March-June 2009) follows a path roughly parallel to the laboratory measurements. It should be noted that the embankment was constructed in 2007, so this period in 2009 would not represent a primary drying curve. The embankment had already been through some drying and wetting history before the instruments were installed. The data is likely to represent a drying scanning curve. While there are differences between the field and laboratory, the general pattern of behaviour seems consistent. 


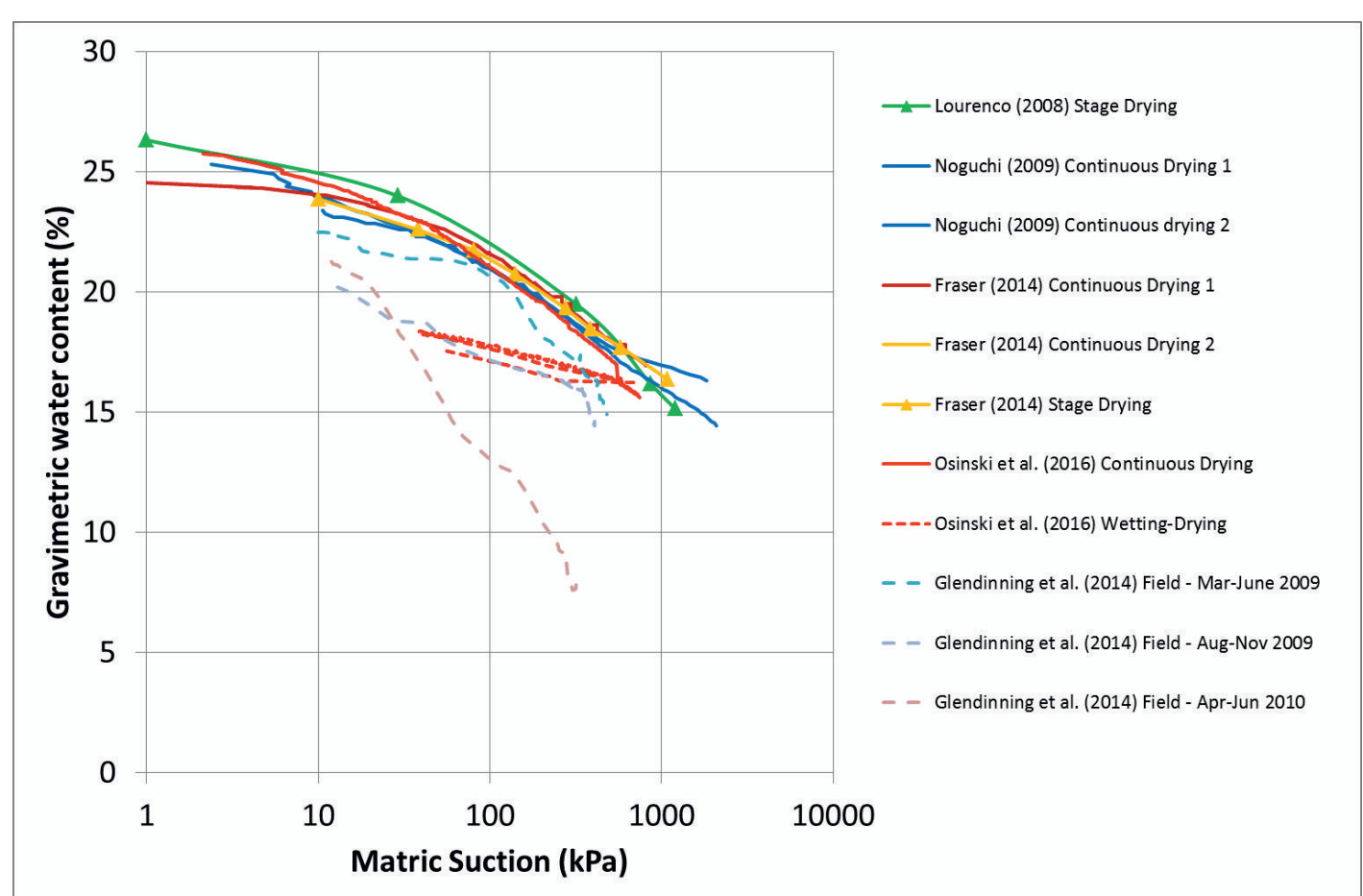

Figure 3. Soil water retention curves from laboratory measurements (tensiometer) and from field observations.

For the wetting period (August-November 2009) the field SWRC seems to follow well the laboratory determined wetting curves. The field wetting continues to a higher water content $(\sim 20 \%)$ and a lower suction $(\sim 10 \mathrm{kPa})$ than was achieved in the laboratory tests.

However, the second drying period (April-June 2010) shows the field data diverging very significantly from the laboratory measurements. The laboratory data shows consistent wetting-drying-wetting paths, showing very little hysteresis between the first and second wetting paths. The field data shows a much steeper path i.e. a much greater water content change for the suction increase to $300 \mathrm{kPa}$.

Further investigations are needed to explain the divergence between the field and laboratory data for this second field drying (April-June 2010). The data will need to be studied in terms of volumetric water content, to see if there are differences in volume change response between the field and laboratory data. As noted by Toll et al. [6], differences in volumetric response can explain differences between types of test to measure water retention behaviour.

\section{Acknowledgements}

The authors wish to acknowledge funding from the Engineering and Physical Sciences Research Council for the BIONICS project (GR/S87430/01) and the iSMART project (EP/K027050/1).

\section{References}

1. Fredlund, D.G. Use of the soil-water characteristic curve in the implementation of unsaturated soil mechanics. Proc. Third Int. Conf. on Unsaturated
Soils, UNSAT 2002, Recife, Brazil. (eds. J.F.T. Juca, T.M.P. de Campos, and F.A.M. Marinho. London: Taylor and Francis, Vol. 3, pp. 887-902. 2002.

2. Hughes, P.N., Glendinning, S., Mendes, J., Parkin, G., Toll, D.G., Gallipoli, D., Miller, P. Full-scale testing to assess climate effects on embankments. Special Issue of Engineering Sustainability: Proc. Institution of Civil Engineers, 162, 2, pp. 67-79. 2009.

3. Mendes, J. Assessment of the impact of climate change on an instrumented embankment: an unsaturated soil mechanics approach. PhD Thesis, Durham University. Available online: http://etheses.dur.ac.uk/612/. 2011.

4. BS1377. Methods of test for Soils of Civil Engineering Purposes, British Standards Institute, Milton Keynes. 1990.

5. Liu, G., Toll, D.G., Kong, L. \& Asquith, J.D. Matric suction and volume characteristics of compacted clay soil under drying and wetting cycles, submitted to ASTM Geotechnical Testing Journal. In press.

6. Toll, D.G., Asquith, J.D., Fraser, A., Hassan, A.A., Liu, G., Lourenço, S.D.N., Mendes, J., Noguchi, T., Osinski, P. \& Stirling, R.A. Tensiometer techniques for determining soil water retention curves. Proc. $6^{\text {th }}$ Asia-Pacific Conference on Unsaturated Soil. Guilin, China. London: Taylor \& Francis (2015)

7. Lourenço, S.D.N., Gallipoli, D., Toll, D.G., Evans, F.D. \& Medero, G.M. Determination of the Soil Water Retention Curve with Tensiometers, in Experimental Unsaturated Soil Mechanics, (ed. T. Schanz), Springer, pp. 95-102. 2007.

8. Lourenço, S.D.N., Gallipoli, D., Toll, D.G., Augarde, C.E. \& Evans, F. 2011. A new procedure for the determination of the Soil Water Retention Curves by continuous drying using high suction tensiometers. Canadian Geotechnical Journal, 48, 2, pp. 327-335.

9. Lourenço, S.D.N., Gallipoli, D., Toll, D.G. and Evans, F.D. Development of a Commercial 
Tensiometer for Triaxial Testing of Unsaturated Soils, Proc. 4th International Conference on Unsaturated Soils, Phoenix, USA, Geotechnical Special Publication No. 147, Reston: ASCE, Vol.2, pp. 18751886. 2006.

10. Toll, D.G., Lourenço, S.D.N. and Mendes, J. Advances in suction measurements using high suction tensiometers, Engineering Geology, 165, pp 29-37. 2013.

11. Toll, D.G. 1999. A data acquisition and control system for geotechnical testing, in Computing Developments in Civil and Structural Engineering (eds. B. Kumar and B.H.V. Topping), Edinburgh: Civil-Comp Press, pp 237-242.
12. Glendinning, S., Hughes, P.N., Helm, P., Chambers, J., Mendes, J., Gunn, D., Wilkinson, P. \& Uhlemann, S. Construction, management and maintenance of embankments used for road and rail infrastructure: implications of weather induced pore water pressures. Acta Geotechnica 9(5): 799. 2014.

13. Osinski, P., Toll, D.G. \& Koda, E. Comparison of Soil Water Retention Curves for sandy clay obtained using different laboratory testing methods. Proc. $3^{\text {rd }}$ European Conference on Unsaturated Soils, Paris. 2016. 